\title{
Prevention of Neural-Tube Defects with Periconceptional Folic Acid, Methylfolate, or Multivitamins?
}

\author{
Andrew E. Czeizel ${ }^{a} \quad$ István Dudás ${ }^{a} \quad$ László Paput $^{b}$ Ferenc Bánhidy $^{c}$ \\ a Foundation for the Community Control of Hereditary Diseases, ${ }^{b}$ Department of Otolaryngology, Head and \\ Neck Surgery, State Health Centre, and 'Second Department of Obstetrics and Gynecology, School of Medicine, \\ Semmelweis University, Budapest, Hungary
}

\section{Key Words}

Neural-tube defects $\cdot$ Folic acid $\cdot$ Methylfolate $\cdot$

Multivitamins - Prevention - Elective termination of affected fetuses

\begin{abstract}
Background/Aims: To review the main results of intervention trials which showed the efficacy of periconceptional folic acid-containing multivitamin and folic acid supplementation in the prevention of neural-tube defects (NTD). Methods and Results: The main findings of 5 intervention trials are known: (i) the efficacy of a multivitamin containing $0.36 \mathrm{mg}$ folic acid in a UK nonrandomized controlled trial resulted in an $83-91 \%$ reduction in NTD recurrence, while the results of the Hungarian (ii) randomized controlled trial and (iii) cohort-controlled trial using a multivitamin containing $0.8 \mathrm{mg}$ folic acid showed 93 and $89 \%$ reductions in the first occurrence of NTD, respectively. On the other hand, (iv) another multicenter randomized controlled trial proved a 71\% efficacy of $4 \mathrm{mg}$ folic acid in the reduction of recurrent NTD, while (v) a public healthoriented Chinese-US trial showed a $41-79 \%$ reduction in the first occurrence of NTD depending on the incidence of NTD. Conclusions: Translational application of these findings could result in a breakthrough in the primary prevention of NTD, but so far this is not widely applied in practice. The benefits and drawbacks of 4 main possible uses of periconceptional folic acid/multivitamin supplementation, i.e. (i) dietary
\end{abstract}

intake, (ii) periconceptional supplementation, (iii) flour fortification, and (iv) the recent attempt for the use of combination of oral contraceptives with 6S-5-methytetrahydrofolate (methylfolate), are discussed. Obviously, prevention of NTD is much better than the frequent elective termination of pregnancies after prenatal diagnosis of NTD fetuses.

Copyright $\odot 2011$ S. Karger AG, Basel

Structural birth defects, i.e. congenital abnormalities (CAs), represent a special category of human disorders due to their very early onset and defect condition; therefore there is a limited chance for the complete recovery of CAs. Thus there is only one optimal approach to CAs in medical practice and it is their prevention.

Neural-tube defects (NTD) are the most frequent and the most tragic CAs of the central nervous system. Fortunately, there was a breakthrough in the prevention of NTD during the 1980s and 1990s via periconceptional folic acid or folic acid-containing multivitamins.

\section{History}

The occurrence of NTD, i.e. anencephaly and spina bifida, depends on the maternal socioeconomic status (low risk in the highest class to above-average risk in the lowest class); thus Smithells et al. [1] hypothesized that

\section{KARGER}

Fax +41613061234 E-Mail karger@karger.ch www.karger.com

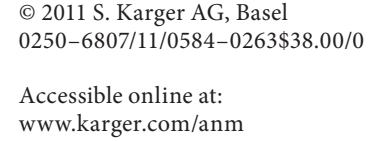

\footnotetext{
Andrew E. Czeizel

Foundation for the Community Control of Hereditary Diseases

Törökvész lejtõ 32

HU-1026 Budapest (Hungary)

Tel. +36 1394 4712, E-Mail czeizel@interware.hu
} 
undernutrition could be the common factor in the origin of NTD. His group tested the effect of diet supplemented with a multivitamin containing $0.36 \mathrm{mg}$ folic acid in the first intervention trial. Women who had had one or more previous infants with NTD were supplemented by this multivitamin during the periconceptional period while controls were recruited among similar women who were already pregnant without vitamin supplementation. The results of this intervention study were published separately for the Yorkshire region of the UK [1] and Northern Ireland [2], and they found 91 and $83 \%$ reductions in NTD recurrence, respectively.

However, their results were not accepted by some experts because of possible selection bias in their non-randomized controlled trial (RCT). Thus the Medical Research Council (MRC) in the UK organized a multicenter RCT (43\% of the participants came from Hungary). There were 4 supplementation groups: folic acid ( $4 \mathrm{mg})$, other vitamins, folic acid + other vitamins, and minerals as the control. The MRC Vitamin Study found that a pharmacological dose (4 mg) of folic acid alone can reduce NTD recurrence by $71 \%$ ( 0.8 vs. $4.3 \%$; RR 0.29 ; $95 \%$ CI $0.12-$ 0.71) [3].

Periconceptional multivitamin supplementation was incorporated into the Hungarian Periconception Service (HPS) launched in 1984 [4] as an RCT. Half of the participants were supplied a micronutrient combination (the so-called 'multivitamin' contained 12 vitamins, among them folic acid $0.8 \mathrm{mg}, \mathrm{B}_{12} 4.0 \mu \mathrm{g}, \mathrm{B}_{6} 2.6 \mathrm{mg}$, and $\mathrm{B}_{2} 1.8 \mathrm{mg}$, 4 minerals, and 3 trace elements), while the other half of the participants were supplied a placebolike trace element combination, i.e. 'no multivitamin', randomly. These women used the supplements at least for 1 month before conception and at least for 2 months after conception because the critical period of anencephaly is between the 35th and 40th gestational days, while spina bifida had this period between the 37 th and 42 nd gestational days.

There were 2 major questions regarding the Hungarian RCT following the publications of the above two 'recurrence' studies: (i) Do folic acid-containing multivitamins reduce the risk of the first occurrence of NTD? About $95 \%$ of women who have a fetus or infant with NTD had no previous NTD pregnancies; thus the prevention of their first occurrence would be a real public health success. (ii) The pharmacological dose (4 mg) of folic acid used in the MRC Vitamin Study might have some adverse effects; thus an objective was to evaluate the physiological dose (1 mg or less) of folic acid. The trial tested the efficacy of a multivitamin containing $0.8 \mathrm{mg}$ folic acid.
NTD did not occur in 2,391 offspring of the multivitamin group, while 6 NTD were found in 2,471 offspring of the no-multivitamin group ( $p=0.01$; RR $0.07 ; 95 \% \mathrm{CI}$ 0.01-0.13). Thus, the Hungarian RCT demonstrated first that a multivitamin containing $0.8 \mathrm{mg}$ folic acid prevented at least $90 \%$ of the first occurrences of NTD [5].

For ethical reasons, the Hungarian RCT could not be continued; thus a cohort-controlled trial (CCT) was designed to collect more data regarding the preventive effect of this multivitamin for NTD and other CAs. All participants in the HPS were supplied the multivitamin used in RCT, while women for the unsupplemented cohort were recruited in the 14th week of pregnancy without vitamin use from the regional prenatal care clinics and they were matched to each pregnant woman of the supplemented cohort. The protective effect of this multivitamin for the reduction of NTD was confirmed in these 3,056 'pairs' (1 vs. 9; OR 0.11; 95\% CI 0.01-0.91) [6].

These Hungarian intervention trials showed the efficacy of this multivitamin in the reduction of some other CAs, and mainly cardiovascular CAs, but these data are not discussed here.

Later, the efficacy of $0.4 \mathrm{mg}$ folic acid for the prevention of the first occurrence of NTD was shown in a Chinese-US study [7]. There was a 79\% reduction in the risk of NTD in areas with high rates of NTD (6.5 per 1,000), while this reduction was $41 \%$ in areas with low rates of NTD $(0.8$ per 1,000$)$.

Many observational studies of folic acid-containing multivitamins or folic acid alone were also published, which confirmed the prevention of NTD, but only the data of intervention trials were summarized above.

\section{Hyperhomocysteinemia-Related NTD}

The origin of NTD can be explained by the interaction of genes and environmental factors (such as dietary deficiency). Several genetic and environmental factors contribute to the origin of NTD; here only the most established one, i.e. hyperhomocysteinemia, is discussed.

The natural polyglutamate folate was discovered by Lucy Wills [8] 80 years ago and she recommended using the term vitamin 11 as a 'twin' of vitamin $B_{12}$. Later the monoglutamate form of this vitamin was synthesized [9]. Humans cannot produce folate. The major dietary sources of folates are fresh and frozen green leafy vegetables, citrus fruits and juices, liver, wheat bread, and legumes such as beans. Thus the requirement of this water-soluble vitamin is supplied partly by dietary intakes of folates 


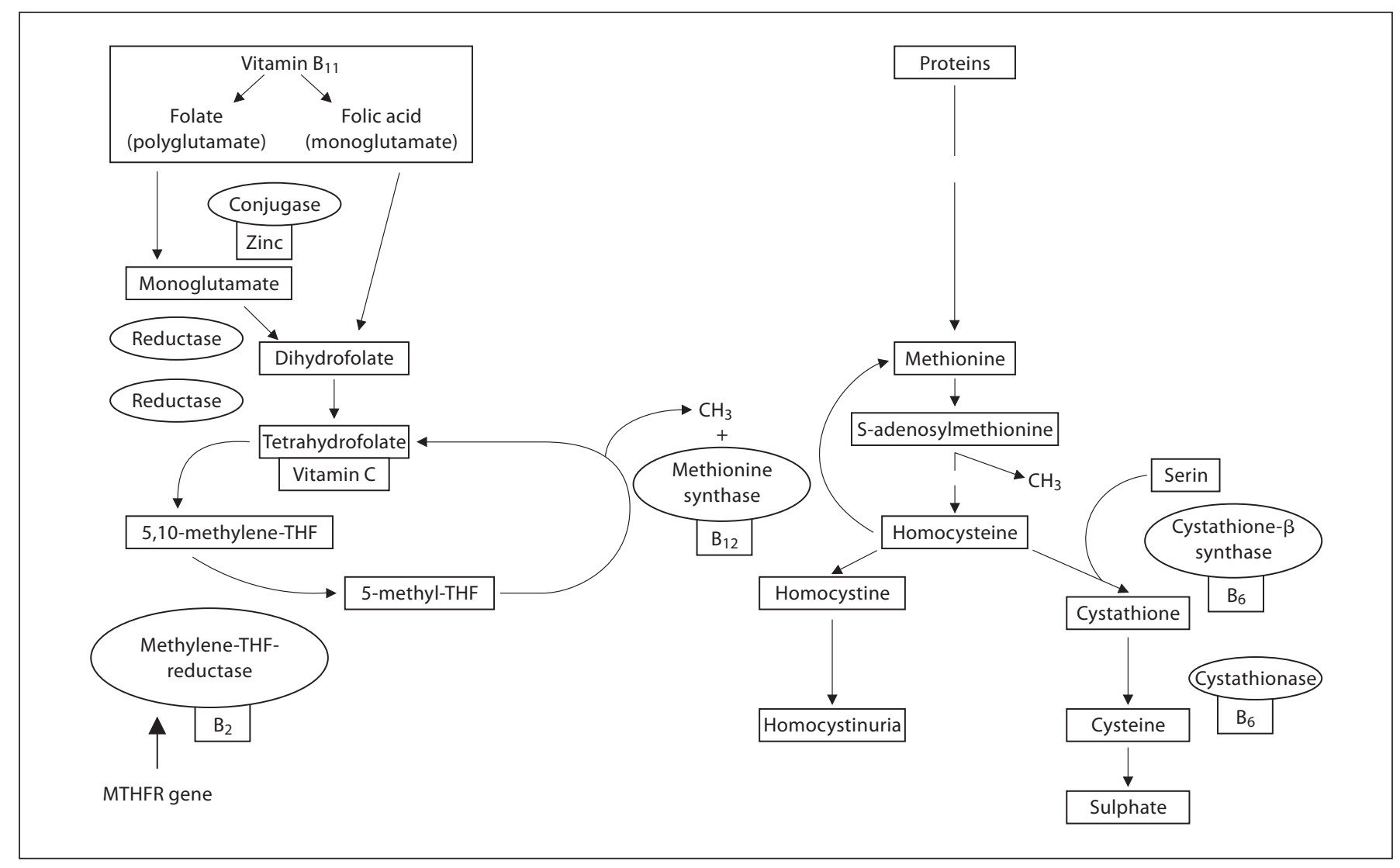

Fig. 1. Metabolism of homocysteine and the effect of folate-folic acid (vitamin $B_{11}$ ), vitamin $B_{12}$, and vitamin $B_{6}$. $\mathrm{CH}_{3}=\mathrm{Methyl}_{\text {group. }}$

and partly by the use of synthetic folic acid, and to estimate doses we have to add these two forms of this vita$\min$.

After dietary intake of polyglutamate folates and the intended supply of synthetic monoglutamate folic acid, these undergo absorption in the cells of the upper small intestine (fig. 1). Folic acid can absorb directly, while folate is changed into the monoglutamate form by conjugase enzymes. In the next step these monoglutamates are converted to dihydrofolate and then to tetrahydrofolate (THF) by reductase enzymes. THF is the parent compound of all biologically active forms of this vitamin. THF is converted to 5,10-methylene-THF and 5-methylene-THF (5-MTHF) before transfer into the hepatic portal vein which then leads to the liver and onwards to the systemic blood circulation and all body tissues.

When meat, fish, or plant proteins are digested, amino acids, e.g. methionine, are released, and methionine is converted to homocysteine. Homocysteine is a toxic metabolite; therefore, humans neutralize it normally as soon as possible. On the one hand, homocysteine is metabolized via the transsulfuration pathway to form cystathionine catalyzed by cystathionine $\beta$-synthase and serine hydroxymethyltransferase. Cystathionine $\beta$-synthase requires pyridoxal $5^{\prime}$-phosphate, i.e. vitamin $\mathrm{B}_{6}$, as a cofactor. On the other hand, remethylation of homocysteine to methionine is catalyzed by methionine synthase. This enzyme requires vitamin $\mathrm{B}_{12}$ as a cofactor and 5-MTHF as the methyl donor. The latter explains the importance of folate-folic acid deficiency in the origin of NTD.

The most important cause of hyperhomocysteinemia and/or a lack of methionine is the polymorphism of the MTHF-reductase (MTHFR) gene. The MTHFR:c.677C $>$ T mutation has been identified and it results in a thermolabile variant (Ala225Val) of the MTHFR enzyme with a $40 \%$ reduction in its activity of CT (heterozygote) and with very low (about $70 \%$ reduction) activity of the TT (homozygote) forms. Vitamin $\mathrm{B}_{2}$ is a cofactor of the MTHRF enzyme. The enzyme variants due to its mutant gene pairs cannot effectively catalyze the pathway of 
5,10-methylene-THF to 5-MTHF, i.e. the methyl donor for methionine synthase. About $10-12 \%$ of the European population is homozygous (TT), while about $40 \%$ are heterozygotes (CT) for this polymorphism of MTHFR gene pairs. The frequency of TT and CT genotypes is 11.1 and $45.2 \%$, respectively, in the Hungarian population [10].

The lower activity of the MTHFR enzyme reduces the production of 5-MTHF and increases the plasma homocysteine level which causes a delay in the closure of the neural tube and thus indirectly NTD. If the mother is a homozygote for this mutation, the risk of NTD is 2-fold; if both the mother and fetus are homozygotes, the risk of NTD increases 6- to 7-fold. Heterozygotes have a slight increase in the risk of NTD.

\section{Practical Use of This New Method for the Prevention of NTD}

There are four approaches to using folic acid or appropriate multivitamins for women of childbearing age who are capable of becoming pregnant.

\section{Consumption of Folate-Rich and Other Vitamin-Rich}

Diets

The usual daily intake of folate is about $0.16-0.20 \mathrm{mg} /$ day in Hungary and this consumption is not significantly higher in other countries. Thus, it is difficult to imagine about a 3.5-fold increase in folate intake every day in anticipation of conception, which would require the consumption of $500 \mathrm{~g}$ raw spinach, $900 \mathrm{~g}$ boiled spinach, or $900 \mathrm{~g}$ raw broccoli, i.e. about 15 servings of broccoli each day. Furthermore, some part of dietary folate is lost through cooking and processing. Finally, an extreme increase in the consumption of extra folate from natural food is relatively ineffective at increasing the folate status [11].

In conclusion, a diet rich in folate is important for the prevention of NTD but cannot alone completely neutralize the genetic predisposition for this CA.

\section{Periconceptional Supplementation}

Substantial evidence is available to advise all women capable of becoming pregnant to have periconceptional (i.e. 2-3 months before and until 3 months after conception) folic acid or folic acid-containing multivitamin supplementation to reduce the occurrence of NTD.

Thus periconceptional use of folic acid or multivitamins would be a simple and useful approach. Nevertheless, this opportunity is missed frequently.
The major problem is that about $50 \%$ of pregnancies are unplanned in the USA, Hungary, and many other industrialized countries.

If women have unplanned pregnancies and are not using a supplement routinely, they cannot take advantage of this new preventive method during the preconceptional period. The explanation is clear: at the time of the first missed menstrual period and on about the 15th postconceptional day, when the possible pregnancy is recognized, the neural tube is preparing to close.

There are two public health tasks to help prospective pregnant women in order to increase their use of periconceptional folic acid or multivitamins. The first is a strong and widespread educational campaign to suggest the start of use of folic acid or multivitamins immediately after discontinuation of oral contraceptive pills or other contraceptive methods when couples decide to have a baby. However, unfortunately these campaigns have had only limited success in all countries [12].

The second important task is to establish a network of pre- or periconceptional care within the primary health care. The HPS was launched in 1984 [4] and the Hungarian RCT and CCT - presented previously - were based on the HPS. We prefer to use the term periconception instead of the usual preconception because prenatal care usually begins in about the 7 th to 12 th week of pregnancy, but the most sensitive and vulnerable time of fetal development is from the 3 rd postconceptional week until the 8 th week, i.e. between the 5 th and 10 th gestational weeks, and this period is omitted from medical health services; thus embryos are uncared for and, in general, unprotected. Pre-/periconceptional care is an optimal infrastructure for the launch of preconceptional folic acid or multivitamin supplementation.

\section{The Dose of Folic Acid}

Based upon the Hungarian RCT and some observational studies, experts in the USA recommended that 'all women of childbearing age who are capable of becoming pregnant should consume $0.4 \mathrm{mg}$ of folic acid per day for the purpose of reducing their risk of having a pregnancy affected by spina bifida or other NTD' [13], and this recommendation was subsequently followed by several countries. However, there was no scientific evidence for the efficacy of this dose in 1992. McPartlin et al. [14] suggested that the optimal daily intake of folate/folic acid for the prevention of NTD in the periconceptional period is about $0.66 \mathrm{mg} /$ day. Daily et al. [15] demonstrated that the lowest risk of having a child with NTD was related to a red blood cell folate concentration of $906 \mathrm{nmol} / \mathrm{l}$ or 
more. However, it was not reached within 4 weeks after the previously recommended $0.4 \mathrm{mg}$ folic acid supplementation; practically 8-12 weeks are needed to reach the recommended level of $906 \mathrm{nmol} / \mathrm{l}$, while the use of $0.8 \mathrm{mg}$ folic acid resulted in the necessary red blood cell folate concentration at $4.2 \pm 3.5$ weeks $[16,17]$.

In our opinion, $1.0 \mathrm{mg}$ of folate/folic acid daily seems to be optimal for all prepregnant and pregnant women, via the consumption of $0.2-0.3 \mathrm{mg}$ folate through diet and via supplementation with $0.7-0.8 \mathrm{mg}$ folic acid.

A Further Dilemma Is the Choice between Folic Acid and Multivitamins

The use of multivitamins containing folic acid and other B vitamins in the Hungarian RCT [5] and CCT [6] and in the study by Smithells et al. [1] showed a higher efficacy (about 90\%) in the reduction of NTD than the MRC Vitamin Study [3] using a high dose of folic acid alone (71\%) and the Chinese-US study [7] using a low dose of folic acid (41-79\%). The usual argument against the use of other vitamins is that the supplementation group of 'other vitamins' in the MRC Vitamin Study [3] did not result in a significant reduction in recurrent NTD. However, it is worth mentioning that there was a $40 \%$ reduction (2.6 vs. $4.3 \%$ ) in recurrent NTD near to the level of significance after supplementation with other vitamins.

Another argument for the use of folic acid-containing multivitamins is that this supplementation is effective for the reduction of some others CAs, but there are very limited data concerning a similar preventive effect of folic acid alone for these CAs.

Finally, hyperhomocysteinemia plays a role in the origin of at least some part of NTD, and vitamins $B_{12}, B_{2}$, and $\mathrm{B}_{6}$ are important cofactors in the folate-homocysteine metabolism (fig. 1).

Obviously, folate/folic acid is a key factor in homocysteine detoxication, but vitamins $\mathrm{B}_{12}, \mathrm{~B}_{2}$, and $\mathrm{B}_{6}$ also have a role in this biological mechanism and it may explain a higher efficacy of a multivitamin including these 4 'fetal protective' B vitamins as folic acid alone in the reduction of NDT.

In conclusion, folic acid-containing multivitamins seem to be more effective in the prevention of NTD, though obviously the use of folic acid alone is more simple and cheaper.

The Last Recent Dilemma: Folic Acid or Methylfolate

After their intake, both natural folate and synthetic folic acid are converted to 5-MTHF and this is the pre- dominant folate form usually found in blood plasma. In recent years, a nature-identical folate of 5-MTHF as 6S5 -MTHF has been synthesized as a calcium salt and marketed as Metafolin ${ }^{\circledR}[18]$. Thus it is a synthetic product but is equal to its natural form; therefore, the term folate is correct.

At present, the use of 6S-5-MTHF seems to be better than the use of folic acid in four aspects:

(i) The previously mentioned polymorphism of MTHFR:c.677C $>\mathrm{T}$ in folate metabolism is associated with an increased risk of NTD, but, in contrast to folic acid, the plasma response of 6S-5-MTHF is not affected in women carrying the common MTHFR:c.677C $>\mathrm{T}$ variant [19].

(ii) The previous major concern regarding the use of folic acid, mainly in higher doses, was its possible masking effect in patients with pernicious anemia. A low concentration of $\mathrm{B}_{12}$ may compromise the activity of methionine synthase (which can reconvert homocysteine back to methionine as a form of 'detoxication'); thus cells suffer a pseudo-folate deficiency that suppresses DNA biosynthesis, which results in the clinical signs and symptoms of megaloblastic anemia. Folic acid bypasses this 'trap' because it can be reduced directly to THF, which can then be cycled to the folate forms used in DNA biosynthesis. This treats the anemia but still allows plasma homocysteine concentrations to rise and continue the interruption to methylation reactions with the possible secondary outcome of demyelination of nerves, resulting in neuropathy. By contrast, supplementation with 6S-5MTHF is not 'trapped', i.e. not recycled to THF, and therefore cannot 'mask' the clinical signs and symptoms of anemia and thus $B_{12}$ deficiency is more likely to be diagnosed and treated [18].

(iii) 6S-5-MTHF may be associated with a reduced interaction with antifolate drugs that inhibit dihydrofolate reductase [20].

(iv) 6S-5-MTHF and folic acid showed comparable physiological activity, bioavailability, and absorption [16]. Thus the equimolar dose of 6S-5-MTHF appears to be at least as effective as folic acid in increasing maternal red blood cell folate concentrations in women of childbearing age $[21,16]$.

On the other hand, human data of controlled epidemiological studies regarding the preventive effect of 6S5-MTHF for NTD are not available.

\section{Food Fortification}

Food fortification seems to be the most practical means of supplementation with folic acid and other vita- 
mins for women with unplanned pregnancies. This public health initiative is comparable to the prevention of goiter by the addition of iodine to salt.

In February 1996, the US Department of Health and Human Services ordered food fortification with folic acid of all cereal grain products at a level of $0.14 \mathrm{mg} / 100 \mathrm{~g}$ beginning January 1998. This adds only about $0.1 \mathrm{mg}$ folic acid to the average daily diet of women of reproductive age; nevertheless, there was a $26 \%$ reduction in the total (birth + fetal) prevalence of NTD [22]. The estimated benefit-cost ratio of US folic acid fortification is 40:1 [23]; thus the estimated economic benefit in US dollars is 312-425 millions annually. Canada also introduced a mandatory flour fortification with folic acid $(0.15 \mathrm{mg} /$ $100 \mathrm{~g}$ of white flour) in September 1998 and a 42\% reduction was found in the total prevalence of NTD [24]. Later many other countries introduced mandatory flour fortification and, as far as we know, at present this public health project exists in 57 countries. However, mandatory flour or other food fortification with folic acid is not available in European countries.

Mandatory flour fortification would be especially important for the large proportion of women with lower levels of education and income who, in general, have difficulty buying more expensive foods rich in folate and other vitamins and who more frequently have unplanned pregnancies.

Our major concern regarding this approach is the low dose of folic acid and the lack of vitamin $\mathrm{B}_{12}$. On the one hand, there is a well-known dose-effect relation in the preventive effect of folic acid for NTD, and it explains that some experts recommend the use of $5 \mathrm{mg}$ folic acid [25]. In our opinion, $0.8 \mathrm{mg}$ is a good compromise. On the other hand, vitamin $\mathrm{B}_{12}$ is an independent risk factor in the origin of NTD, and the combination of folic acid and vitamin $\mathrm{B}_{12}$ can prevent the so-called 'masking effect' of folic acid in patients with pernicious anemia.

However, there are two other opposite opinions regarding flour fortification with folic acid. Results of studies showed that folate deficiency is a precancerous state, but recent data suggested a possible carcinogenic effect of high doses of folic acid as well. Thus there may be a U-shaped risk of cancer connected with the doses of folic acid [26]. Some experts therefore did not recommend the introduction of flour fortification by folic acid because it may be associated with risk in older people with precancerous lesions, e.g. in the colon. The opposite opinion is based on the good experiences with flour fortification in the USA and Canada; thus Oakley [27] declared that inertia in folic acid fortification is a public health malpractice.

\section{Combination of Oral Contraceptives and Folate}

Periconceptional folic acid or folic acid-containing multivitamin supplementation requires planned conception, and the proportion of females who prepare for conception is between only 30 and $75 \%$ in different countries.

The combination of oral contraceptive pills with folate is another option [28]. Recently, the US FDA (Food and Drug Administration) approved a new medicinal product comprised of drospirenone and ethinyl estradiol as contraceptive components and levomefolate calcium as a folate component.

Four advantages can be expected from this new approach:

(i) Overall, 30-50\% of women between the ages of 15 and 49 years take oral contraceptives in most Western European countries [29]. Information on the beneficial effects of folic acid or folic acid containing multivitamins could and should be provided on the contraceptive packet. Thus our hope is that the user of this medicinal product will have better knowledge to understand that the start of the use of folic acid or multivitamins immediately after the discontinuation of oral contraceptive pills is necessary when couples decide to have a baby.

(ii) It is a well-known fact that the compliance of pill use is not prefect, e.g. only $42 \%$ of oral contraceptive users remembered to take their pill every day [30]. Thus inadvertent 'accidental' conception may occur in about $2 \%$ of women who use contraceptive pills; the parallel use of folate is important for the prevention of NTD in their fetuses.

(iii) Studies showed that $42 \%$ of women who discontinued pill use did not consult with their health care provider [31]. In addition, about $60 \%$ of young females who used oral contraceptives and stopped in order to have their first pregnancy had no connection with gynecologists in Hungary [4].

(iv) The European Active Surveillance Study (EURAS) evaluated 2,000 women who stopped taking oral contraceptives in order to become pregnant [32], and 31\% were pregnant within the first month after stopping oral contraceptive use and $46 \%$ after 3 months. In another study, conception occurred within 2 months after the cessation of oral contraceptive use in $30-40 \%$ of all pregnancies and within 4 months in 50-60\% [33]. Thus an important benefit is that women who discontinued the use of a combination of contraceptive pills and folate have a higher blood folate level - albeit, of course, with a decline parallel with time. This 'post-use effect' may be useful to reduce the risk of NTD. 
However, while the plasma folate level reflects the intake of folate/folic acid in previous days, the red blood cell folate level shows a more constant, characteristic level because its change is slow within the 120-day life of erythrocytes. Thus it is understandable that the plasma folate concentration has a faster decrease after the discontinuation of oral contraceptives, and it is important to know that the cells of the fetus are exposed to circulating plasma folate.

In conclusion, the expected benefits of combined oral contraceptives with folate can be defined, while it is difficult to estimate the possible unexpected risks; thus the introduction of this new medicinal product for the prevention of NTD in the most important target group, women of reproductive age, seems to be promising.

Food fortification with folic acid and the combination of oral contraceptives with folate would be important because the beneficial effect of periconceptional folic acid/multivitamin supplementation has not been used widely and appropriately for the prevention of NTD in medical practice. In addition, there was significant improvement in the prenatal diagnosis of fetuses affected with NTD.

\section{Prenatal Diagnosis of Fetuses Affected with NTD}

Before the 1960s nearly all victims of NTD had fatal outcomes. In the 1960s physicians introduced very early complex surgical and medical interventions and the lives of victims were saved in the majority of spina bifida cases (of course, anencephaly has remained lethal). In the 1970s the selective criteria of surgical intervention in cases with spina bifida was introduced to reduce the production of multiply handicapped children.

In the 1980s prenatal screening based on maternal serum $\alpha$-fetoprotein (MS-AFP) was introduced for the detection of NTD in fetuses. In low-risk populations the detection rate (i.e. sensitivity) of MS-AFP testing for open NTD varies from 72 to $91 \%$ and the specificity from 96.2 to $98.7 \%$ [34]. Since the early 1990 s there has been great progress in the efficacy of ultrasound diagnosis in the detection of NTD in fetuses. However, overall only 10 $40 \%$ of all spina bifida cases are picked up during routine screening and even anencephaly may be missed in first trimester scans [28]. However, all anencephalic fetuses are diagnosed by ultrasound in the second trimester, and about $80 \%$ of fetuses affected with spina bifida are also diagnosed on the basis of the so-called 'lemon' and 'banana' signs which are characteristic changes in the head of affected fetuses. Mainly the diagnosis of fetuses with closed spina bifida is missed.

After the prenatal diagnosis of NTD, informed pregnant women have to choose between two evils: continuing their pregnancy with the long-term medical, psychological, and financial consequences of their multiply handicapped children or deciding to terminate their pregnancy at about the end of the second trimester, when their moving fetuses are expected very much. Our study showed that $99 \%$ of pregnant women with anencephalic fetuses and $97 \%$ of women who had diagnosed fetuses with spina bifida decided to terminate their pregnancy.

Finally, since the late 1990s, we have had a chance to reduce the maldevelopment of the neural tube due to intentional modification (supplementation) of the diet by folic acid or folic acid-containing multivitamins in the periconceptional period of life.

Previously, we estimated the proportion of pregnant women with folic acid/multivitamin supplementation between 1980 and 1996 [35]. The rate of folic acid/multivitamin supplementation use was $52.4 \%$ after the first visit to a prenatal care clinic, but the estimated proportion of women with preconceptional folic acid/multivitamin supplementation was only $12 \%$. Nevertheless, there was a robust drop in the total prevalence of recorded cases with NTD in the Hungarian Congenital Abnormality Registry because $76.9 \%$ of cases with NTD were found in the group of elective termination of pregnancy after their prenatal diagnosis and only about $5 \%$ of NTD cases were prevented by periconceptional folic acid/multivitamin supplementation in 2008 [36].

At present, periconceptional folic acid or folic acidcontaining multivitamin supplementation as a preventive method against NTD offers an optimal medical alternative compared with elective termination of NTD fetuses for the following reasons:

(i) The efficacy of these two methods is nearly the same: folic acid can prevent about $70 \%$ of NTD conceptions while folic acid-containing multivitamin can prevent about $90 \%$, and the diagnostic efficacy of ultrasound is nearly $100 \%$ in anencephalic fetuses and about $80 \%$ in fetuses with different manifestations of spina bifida.

(ii) The cost of multivitamins and particularly folic acid is much lower than that of prenatal diagnosis of an NTD fetus followed by elective termination of the pregnancy.

(iii) The risks of folic acid/multivitamin use are minimal, while the early complications and late adverse consequences of pregnancy terminations cannot be neglected. 
(iv) Elective termination of pregnancy due to NTD fetuses between the 16th and 20th gestation weeks induces serious psychological crises in many pregnant women. Similar problems do not occur in pregnant women with folic acid/multivitamin use.

(v) Termination of pregnancy due to NTD fetuses associates with a moral dilemma in several people including females and medical doctors. In contrast, the birth of a healthy baby after periconceptional folic acid/multivitamin supplementation results in great happiness and improved self-esteem [4].

\section{Conclusion}

Obviously, prevention of NTD is much better than elective termination of a pregnancy after the prenatal diagnosis of NTD; thus we have to do our best to change the present trends. This review paper wants to promote this activity confirmed by the truth of the old English proverb: 'An ounce of prevention is better than a pound of care'. However, it is necessary to educate prospective parents on the appropriate use of periconceptional folic acid/ multivitamin supplementation $[0.8 \mathrm{mg}$ folic acid instead of the previously recommended $0.4 \mathrm{mg}$ folic acid or using the most effective folic acid $(0.8 \mathrm{mg})$-containing multivitamins] to prevent NTD in medical practice.

\section{References}

1 Smithells RW, Sheppard S, Wild J, Schorah CJ: Prevention of neural tube defect recurrences in Yorkshire: final report. Lancet 1989;2:498-499.

-2 Nevin NC, Seller MJ: Prevention of neural tube defect recurrences. Lancet 1990;1:178179.

-3 MRC Vitamin Study Research Group: Prevention of neural tube defects: results of the Medical Research Council Vitamin Study. Lancet 1991;338:131-137.

$\checkmark 4$ Czeizel AE: Ten years of experience in the periconceptional care. Eur J Obstet Gynecol Reprod Biol 1999;89:43-49.

5 Czeizel AE, Dudás I: Prevention of the first occurrence of neural-tube defects by periconceptional vitamin supplementation. $\mathrm{N}$ Engl J Med 1992;327:1832-1835.

-6 Czeizel AE, Dobó M, Vargha P: Hungarian cohort controlled trial of periconceptional multivitamin supplementation shows a reduction in certain congenital abnormalities. Birth Defects Res A Clin Mol Teratol 2004; 70:853-861.

7 Berry RJ, Li Z, Erickson JD, Li S, Moore CA, Wang H, Li S, Moore CA, Wang H, Mulinare J, Zhao P, Wong LY, Gindler J, Hong SX, Correa A: Prevention of neural-tube defects with folic acid in China: China-US Collaborative Project for Neural Tube Defect Prevention. N Engl J Med 1999;341:1485-1490.

8 Wills L: Treatment of 'pernicious anaemia' of pregnancy and 'tropical anaemia' with special reference to yeast extract as a curative agent. Br Med J 1931;1:1059-1064.

$\checkmark 9$ Hoffbrand AV: The history of folic acid. Br J Haematol 2001;113:579-589.

-10 Wilcken B, Bamforth F, Li Z, Ritvanen A, Redlund M, Stoll C, Alembik Y, Dott B, Czeizel AE, Gelman-Kohan Z, Scarano G, Bianca S, Ettore G, Tenconi R, Bellato S, Scala I, Mutchinick OM, López MA, de Walle $\mathrm{H}$, Hofstra R, Joutchenko L, Kavteladze L, Bermejo E, Mar-
tinez-Frias ML, Gallagher M, Erickson JD, Vollset SE, Mastroiacovo P, Andria G, Botto LD: Geographical and ethnic variation of the $677 \mathrm{C} / \mathrm{T}$ allele of 5,10 methylenetetrahydrofolate reductase (MTHFR): findings from over 7,000 newborns from 16 areas world wide. J Med Genet 2003;40:619-625.

11 Cuskelly GJ, McNulty H, Scott JM: Effect of increasing dietary folate on red-cell folate: implications for prevention of neural tube defects. Lancet 1996;347:657-659.

12 Busby A, Abramsky L, Dolk H, Armstrong B, Addor MC, Anneren G, Armstrong N, Baguette A, Barisic I, Berghold A, Bianca S, Braz P, Calzolari E, Christiansen M, Cocchi G, Daltveit AK, De Walle H, Edwards G, Gatt M, Gener B, Gillerot Y, Gjergja R, Goujard J, Haeusler M, Latos-Bielenska A, McDonnell R, Neville A, Olars B, Portillo I, Ritvanen A, Robert-Gnansia E, Rösch C, Scarano G, Steinbicker V: Preventing neural tube defects in Europe: a missed opportunity. Reprod Toxicol 2005;20:393-402.

13 CDC: Recommendations for the use of folic acid to reduce the number of cases of spina bifida and other neural tube defects. MMWR 1992;41:1233-1238.

14 McPartlin J, Halligan A, Scott JM, Garling M, Weir DG: Accelerated folate breakdown in pregnancy. Lancet 1993;341:148-149.

15 Daily LE, Kirke PN, Molloy A, Weir DG Scott JM: Folate levels and neural tube defects. Implications for prevention. JAMA 1993;274:1698-1702.

16 Pietrzik K, Lamers Y, Brämswig S, PrinzLangenohl R: Calculation of red blood cell folate steady state conditions and elimination kinetics after daily supplementation with various folate forms and doses in women in childbearing age. Am J Clin Nutr 2007; 86:1414-1419.

-17 Brämswig S, Prinz-Langenohl R, Lamers Y, Tobolski O, Wintergerst E, Berthold HK,
Pietrzik K: Supplementation with a multivitamin containing 800 microg of folic acid shortens the time to reach the preventive red blood cell folate concentration in healthy women. Int J Vitam Nutr Res 2009; 79:61-70.

18 Wright AJ, King MJ, Finglas PM: Folate-supplemented oral contraceptives: does 6S-5methytetrahydrofolic acid (Metafolin ${ }^{\circledR}$ ) offer advantages over folic acid? Gynaecol Forum 2010;15:29-32.

19 Prinz-Langenohl R, Brämswig S, Tobolski O, Smulders YM, Smith DE, Finglas PM, Pietrzik K: [6S]-5-methyltetrahydrofolate increases plasma folate more effectively than folic acid in women with homozygous or wild-type $677 \mathrm{C}-\mathrm{T}$ polymorphism of methylenetetrahydrofolate reductase. Br J Pharmacol 2009;158:2014-2021.

20 Pietrzik K, Bailey L, Shane B: Folic acid and L-5-methyltetrahydrofolate: comparison of clinical pharmacokinetics and pharmacodynamics. Clin Pharmacokinet 2010;49:535548

21 Lamers Y, Prinz-Langenohl R, Brämswig S, Pietrzik K: Red blood cell folate concentrations increase more after supplementation with [6S]-methyltetrahydrofolate than with folic acid in women of childbearing age. Am J Clin Nutr 2006;84:156-161.

22 Williams LJ, Mai C, Edmonds LD, Shaw GM, Kirby RS, Hobbs CA, Sever LE, Miller LA, Meaney FJ, Levitt M: Prevalence of spina bifida and anencephaly during the transition to mandatory folic acid fortification in the United States. Teratology 2002;66: 33-39.

23 Grosse SD, Waltzman NJ, Romano PS, Mulinare J: Reevaluating the benefits of folic acid fortification in the United States: economic analysis, regulation, and public health. Am J Public Health 2005;95:19171922. 
-24 De Wals P, Tairou F, Van Allen M, Uh SH, Lowry RB, Sibbald B, Evans JA, Van den Hof MC, Zimmer P, Crowley M, Fernandez B, Lee NS, Niyonsenga T: Reduction in neuraltube defects after folic acid fortification in Canada. N Engl J Med 2007;357:135-142.

25 Wald NJ, Law MR, Morris JK, Wald DS: Quantifying the effects of folic acid. Lancet 2001;358:2069-2073.

26 Fenech M: The role of folic acid and vitamin $\mathrm{B}_{12}$ in genomic stability of human cells. $\mathrm{Mu}-$ tat Res 2001;475:57-67.

-27 Oakley GP: Inertia on folic acid fortification: public health malpractice. Teratology 2002; 66:44-54.

28 Holzgreve W: Adding folate to the pill to prevent neural tube defects. Gynaecol Forum 2010;15:4-8.
29 Szarevsky A: Oral contraceptive and pregnancy planning. Gynaecol Forum 2010;15 23-28.

30 Oakley D, Sereika S, Bogue EL: Oral contraceptive pill use after an initial visit to a family planning clinic. Fam Plann Perspect 1991; 23:151-154.

31 Rosenberg MJ, Waugh MS: Oral contraceptives discontinuation: a prospective evaluation of frequency and reasons. Am J Obstet Gynecol 1998;179:577-582.

32 Cronin M, Schellschmidt I, Dinger J: Rate of pregnancy after using drosperinone and other progestin-containing oral contraceptives. Obstet Gyneco 2009;114:616-622.

33 Dunson DB, Baird DD, Colombo B: Increased infertility with age in men and women. Obstet Gynecol 2004;103:51-56.
34 Periodic health examination, 1994 update. 3. Primary and secondary prevention of neural tube defects - Canadian Task Force on the Periodic Health Evaluation. CMAJ 1994;151: 21-28.

35 Czeizel AE, Vargha P: Periconceptional folic acid/multivitamin supplementation and twin pregnancy. Am J Obstet Gynecol 2004; 1891:790-794.

36 Valek A, Béres J, Métneki J: Efficiency of prenatal screening of congenital abnormalities on the basis of the Hungarian Congenital Abnormality Registry and Surveillance. Magy Epidemiol 2010;7:S11-S12. 